\title{
Brain abscess and granuloma formation as late complications of retained ventricular catheter
}

\author{
S. A. Khan, A. Gretchel, H. Govender, B. Hartzenberg \\ Division of Neurosurgery, Tygerberg Academic Hospital, Capetown, South Africa
}

\author{
Address for correspondence: \\ Dr. Shahid Ahmed Khan, \\ Department of Neurosurgery, \\ A 4 West, Fourth Floor, Tygerberg \\ Hospital, Private Bag-X 3, Tygerberg \\ 7505, Cape Town, South Africa. \\ E-mail: drahmed22@yahoo.com
}

DOI: $10.4103 / 0028-3886.55604$

\begin{abstract}
This report presents a rare complication of ventriculoperitoneal shunt, delayed development of brain abscess and foreign body granuloma formation adjacent to the intraventricular catheter. Both the complications occurring in the same patient is unusual.
\end{abstract}

Key words: Brain abscess, foreign body granuloma formation, nonfunctioning, rare

\section{Introduction}

Ventriculoperitoneal shunt (VPS) is the standard procedure for the treatment of obstructive and communicating hydrocephalus in neurosurgical practice and the procedure is associated with numerous complications. Obstruction, infection, over and under shunting, and disconnection remain the most common complication. ${ }^{[1-3]}$ Cerebral abscess and granuloma formation are very rare complications associated with the shunt system. ${ }^{[2]}$ We discuss a patient who developed both these two complications together.

\section{Case Report}

A 37-year-old male sustained head injury in the year 1987 following which he developed post-traumatic hydrocephalus for which he was treated by insertion of a right frontal VPS. Subsequent to this he had sustained head injuries on two occasions, in 1993 and April 2002. In 1995 (allegedly assaulted), he started to have seizures (posttraumatic), the frequency of which gradually increased in the following years. A CT scan (scout view), done in April 2002, revealed non-functioning frontal VPS, the proximal intraventricular catheter was disconnected from the distal system. Subsequently he became symptomatic (hydrocephalus) for which he was operated and a right occipital VPS was placed. However, the frontal intraventricular catheter was left in situ for the possible fear of bleeding on removal. Five years later, in August 2007 , the patient presented with headache and drowsiness.

Clinical examination revealed a Glasgow coma scale of 15/15; he had bilateral papilledema, but no neurological deficit. Contrast CT scan showed a complex contrast ring enhancing mass lesions in the right frontal lobe in close association with the frontal catheter. There was perilesional edema with the effacement of frontal horn and moderate midline shift [Figures 1 and 2]. Contrast magnetic resonance imaging (MRI) demonstrated a solid enhancing tissue surrounding the shunt and a ring enhancing lesion [Figure 2]. Preoperative,septic profile showed increased $C$ reactive protein and white cells. Steroids were initiated to reduce the mass effect of the edema. Subsequently the patient underwent craniotomy for excision of this complex mass and the associated abscess. At operation the ring enhancing lesion was a rubbery brownish tissue surrounded by well-defined planes of tissues that were dissected successfully. Two cystic cavities filled with pus were dissected. The entire lesion was excised successfully. The old frontal shunt catheter was delivered out without any difficulty and there was no bleeding seen from the intracerebral shunt tract. The new occipital shunt system was left in situ. The pus was sent to microbiological studies for bacteria, fungus, and tuberculosis. Postoperatively the patient improved gradually. Follow-up CT scans showed no evidence of enhancing lesion. There was a mild 
resolving brain swelling. Three specimens, A, B, and C, were sent for histological studies. Specimen A showed brown tissues with reactive gliosis and polymorphic inflammatory cell infiltrate comprising neutrophils, lymphocytes, plasma cells (some of them with Russel bodies), and macrophages. A prominent perivascular cuffing was present [Figure 3]. In some areas, there were extensive hyalinized tissues as well as granulomatous inflammation comprising epithelioid cells, foreign body giants cells, and lymphocytes. Cholesterol clefts and
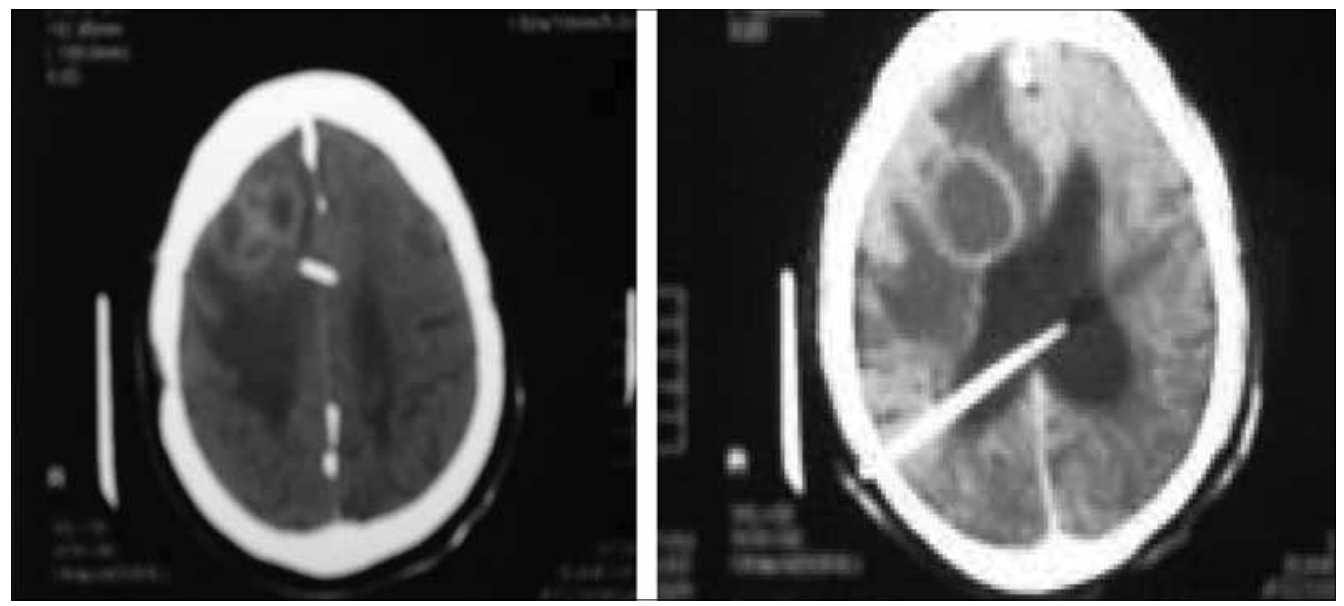

Figure 1: Contrast CT scan, August 2007, showing a ring enhancing lesion in the frontal area around the frontal (old) catheter and the new occipital catheter in situ
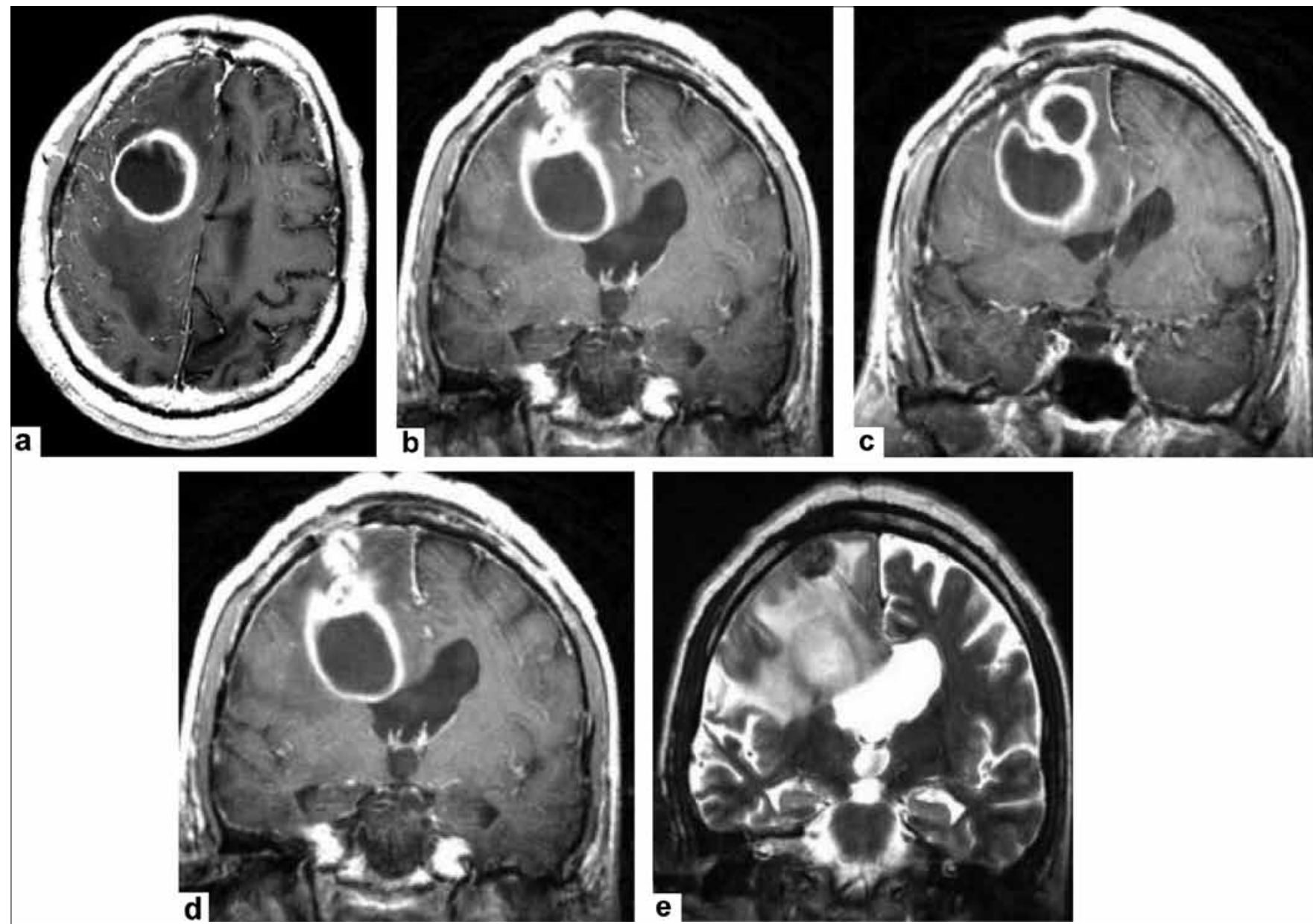

Figure 2: Brain MRI demonstrating (a) Corresponding T1 + C is unremarkable for pyogenic abscess; (b, c) Coronal contrast views show solid enhancing tissue surrounding the shunt immediately below burr-hole defect (L), and complex loculation (R); (d, e) Peri-shunt mass with diffuse enhancement (L), is T2 hypointense (R), reflecting signal loss associated with inflammatory granulation tissue 

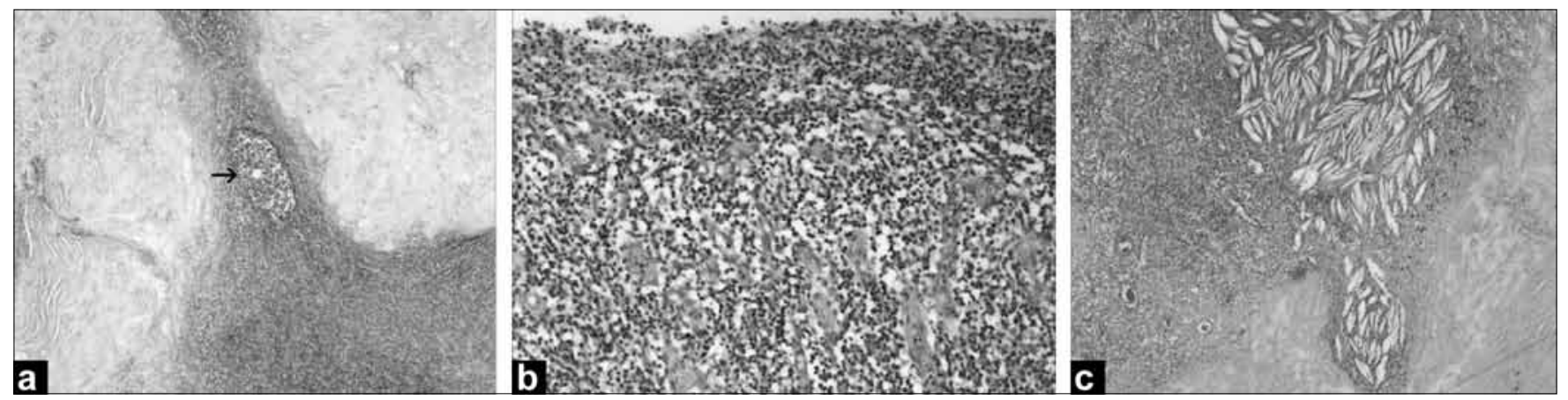

Figure 3: (a) Low-power micrograph depicting hyalinized connective tissue enclosing cellular inflammatory granulation tissue, with central eosinophilic microabscess (arrow), $\mathrm{H}$ and $\mathrm{E}, \times 100$; (b) Detail of large cavity showing inflammatory granulation tissue lined by partially necrotic eosinophils, $\mathrm{H}$ and $\mathrm{E}, \times 200$; (c) Focal aggregate of cholesterol crystals, with adjacent hemosiderophages, denoting old hemorrhage, $\mathrm{H}$ and $\mathrm{E}, \times 100$

calcospherites were also present. All the features were consistent with foreign body granuloma. Specimen B contained tissue surrounding the abscess wall. There was reactive gliosis with chronic inflammatory cells. Specimen C contained tissue of the abscess wall. There was a thick collagenous capsule with surrounding granulation tissue. Pus demonstrated Gram-positive cocci Staphlococcus aureus, sensitive to cloxacillin. No growth of fungus or mycobacteria was seen.

\section{Discussion}

Ventriculoperitoneal shunt is a life-saving procedure for patients with obstructive or communicating hydrocephalus, however is associated with various pathological complications. Cerebral abscess formation related to shunt system is one of the known but an unusual complication. ${ }^{[6]}$ The source of infection is in the distal end of shunt system and ascends through the shunt resulting in abscess formation, meningitis, and subdural empyema. ${ }^{[4]}$ In most of the patients colonic perforation and the ascent of enteric organisms is considered as the possible mechanism of brain abscess formation $^{[6]}$ This patient had three rare and unusual presentations: (1) an extremely delayed presentation of unusual complications of VPS; (2) the cerebral abscess was related to a nonfunctional intraventricular catheter disconnected from the distal system for a long time; (3) rare combination of pathology, cerebral abcess and granuloma, foreign body reaction to the catheter material. The intracranial granuloma formation with the associated pathology was consistent with all the features of chronic inflammatory reaction adjacent to a foreign body. Both these complications presenting together makes this case unique. Korosuet et al. reported a case of an intracranial granuloma formation as an unusual complication of subdural peritoneal shunt. ${ }^{[7]}$

Sepsis is one of the major complications associated with the use of shunt devices. Shunt-related sepsis can be categorized into localized and generalized, the latter being the commonest category of shunt-related sepsis.
Ventricular catheter infection can be hematogenous, contiguous along the shunt tract from abdominal sources and contamination of shunt devices with the skin flora at the time of surgery. The commonest organisms causing shunt infections are S. epidermis and S. aureus. In case of enteric organisms such as Escherichia coli, Proteus, and Klebsiella, the most probable source is the abdomen. Although it is related generally with bowel perforation, but in some cases the bowel may be intact. A majority of shunt-related (generalized) infections are managed by surgical removal of the infected shunt device and the use of intravenous antibiotics. Localized shunt-related sepsis is rare and usually presents very late. The source of localized shunt infection is usually the perforated colon. However, it appears that the mechanism in the cases reported earlier in the literature, was untreated shunt infection rather than the colonic perforation. ${ }^{[8]}$ There have been few cases reports of nonfunctional intraventricular catheter as a cause of shunt-related abscess formation. In these patients the catheters were left behind as they were considered dormant and subsequently they were found to be the source of brain abscess formation at a late or very late stage (one case had fatal ventriculitis)..$^{[9,10]}$

The principles of management of localized shunt-related sepsis are the same like any cerebral abscess: Systemic intravenous antibiotics, needle aspiration or excision of the abscess or granuloma by craniotomy. Ventricular hardware has also to be removed. Removing the ventricular catheter adherent to the choroid plexus may be problematic and removal may be associated with major bleeding. We suggest to remove the ventricular catheter under direct vision, particularly when the cerebral abcess is in communication or in close proximity to the ventricles. The other option will be to remove the ventricular catheter by neuroendoscopy and to avoid bleeding coagulation of the choroid plexus may be considered. ${ }^{[11]}$ Neuroendoscopic removal of ventricular catheter may not be possible in all the cases. However advancement in the neuroendoscopy is opening an additional option in dealing with complicated and difficult cases of nonfunctional catheter in situ. In our case report, brain abscess and granuloma were excised by 
craniotomy and the old frontal ventricular catheter was taken out. The frontal horn was not opened as the abscess cavity was not in communication with the anterior horn of the lateral ventricle. While dissecting the abscess and granuloma, the shunt catheter delivered by itself without any difficulty and it was presumed that the shunt catheter was not attached to the choroid plexus. Perioperatively, no bleeding was noticed from the tract after the catheter was out.

This patient had right frontal VPS in 1987. This shunt was found to be disconnected in 2002 and a right occipital VPS was inserted while the old frontal intraventricular catheter was left in situ, considering the possible complication of intracranial bleeding, especially when this shunt had been in situ for 15 years. ${ }^{[5]}$ The total duration of the frontal VPS in this patient was 20 years and it was non-functional for the last five years. Thus the possibility of spread of enteric organisms from the bowel is very unlikely.

\section{References}

1. Aguiar PH, Shu, Freitas AB, Leme RJ, Miura FK, Marino R Jr. Causes and treatment of intracranial haemorrhage complicating shunting for pediatric hydrocephalus. Child Nerv Syst 2000;16:218-21.

2. Arrese I, Nuñez AP, Rivas JJ, Lobato RD. Absceso cerebral tardio como complication de una derivacion ventriculo-peritoneal. Neurosciruga (Astur) 2004;15:472-5.

3. Choux M, Genitori L, Lang D, Lena G. Shunt implantation: Reducing the incidence of shunt-infections. J Neurosurg 1992;77:875-80.

4. Dickerman RD, Piatt JH, Hsu F, Frank EH. Subdural empyema complicating cerebrospinal fluid shunt infection. Pediatr Neurosurg 1999;30:310-1.

5. Epstein F. Diagnosis and management of arrested hydrocephalus. Monogr Neural Sci 1982;8:227-8.

6. Gower DJ, Horton D, Pollay M. Shunt related brain abscess and ascending shunt infection. J Child Neurol 1990;5:318-20.

7. Korosue K, Tamaki N, Matsumoto S, Ohi Y. Intracranial granuloma as an unusual complication of subdural peritoneal shunt. J Neurosurg $1981 ; 55: 136-8$

8. Erashin Y, Yurtseven T. Rare complication of shunt infection. Pediatr Neurosurg 2004;40:90-92.

9. Gupta R, Mohindra S, Dhingra AK. Are non-functioning intraventricular shunt catheters really dormant? Br J Neurosurg 2007;21:297-8.

10. Vougioukas VI, Feuerhake F, Hubbe U, Reinacher P, Van Velthoven V. Latent abscess formation adjacent to a non-functioning intraventricular catheter. Childs Nerv Syst 2003;19:119-21.

11. Shin DS, Hwang SC, Kim BT, Shin WH. Delayed cerebral abscess as a shunt complication and endoscopic removal of the ventricular catheter and abscess. J Korean Neurosurg Soc 2008;43:300-3.

Accepted on 16-03-2009

Source of Support: Nil, Conflict of Interest: None declared. 